\title{
Seeded Photoinitiated Polymerization-Induced Self-Assembly: \\ Cylindrical Micelles with Patchy Structures prepared via the Chain- Extension of a Third Block
}

\author{
Xiaocong Dai ${ }^{\mathrm{a}}$, Yuxuan Zhang ${ }^{\mathrm{a}}$, Liangliang Yu', Xueliang Li ${ }^{\mathrm{a}}$, Li Zhang ${ }^{\mathrm{a}, \mathrm{b}}$, Jianbo Tan ${ }^{\text {a,b }}$ \\ a. Department of Polymeric Materials and Engineering, School of Materials and Energy, Guangdong \\ University of Technology, Guangzhou 510006, China. \\ b. Guangdong Provincial Key Laboratory of Functional Soft Condensed Matter, Guangzhou 510006, China.
}

*Corresponding authors: tanjianbo@gdut.edu.cn

Xiaocong Dai and Yuxuan Zhang contributed equally to this work. 


\section{EXPERIMENTAL SECTION}

\section{Materials.}

Glycidyl methacrylate (GlyMA, Aladdin), methyl methacrylate (MMA, Aladdin), benzyl methacrylate (BzMA, Aladdin), tert-Butyl acrylate ( $t$ BA, Aladdin) were purified by passing through a basic alumina oxide (Aladdin) column prior to storage at $4{ }^{\circ} \mathrm{C}$. Poly(ethylene glycol) methyl ether methacrylate (PEGMA, $M_{\mathrm{n}}=500 \mathrm{~g} / \mathrm{mol}$, Aladdin), hydroxypropyl methacrylate (HPMA, Aladdin), ethylene diamine (EDA, Tianjin Damao), 3-mercaptopropionic acid (3-MPA, Aladdin), hydroquinone (Aladdin), sodium dodecyl sulfate (SDS, Aladdin), n-hexane (Tianjin Damao), dodecane (Tianjin Damao), 1,4-dioxane (Tianjin Damao), 1,3,5-trioxane (Aladdin), and N, $N$-dimethylformamide (DMF, Tianjin Damao) were used without further purification. 2, 2-Azobisisobutyronitrile (AIBN, Aladdin) was recrystallized from ethanol prior to storage under refrigeration at $4{ }^{\circ} \mathrm{C}$. $\mathrm{N}$-isopropylacrylamide (NIPAM, Aladdin) was recrystallized from n-hexane prior to storage under refrigeration at $4{ }^{\circ} \mathrm{C} .4-$ cyano-4-(dodecylsulfanylthiocarbonyl)sulfanylpentanoic acid (CDPA) was synthesized according to a published procedure. ${ }^{1}$ Allyl Acrylamide (ALAM) was synthesized according to a published procedure. $^{2}$ Sodium phenyl-2,4,6-trimethylbenzoylphosphinate (SPTP) was also synthesized according to a published procedure. ${ }^{3}$

\section{Characterization.}

${ }^{\prime} H$ NMR Spectroscopy. Nuclear magnetic resonance (NMR) spectra were recorded in $d_{6}$-DMSO or $\mathrm{CDCl}_{3}$ using a Bruker Avance III $400 \mathrm{MHz} \mathrm{NMR}$ spectrometer at a temperature of $25^{\circ} \mathrm{C}$. In all aqueous photo-PISA formulations, sodium 2,2-dimethyl2-silapentane-5-sulfonate was utilized as internal standard.

Transmission Electron Microscopy (TEM). The obtained samples were diluted with water. A drop of the dispersion was placed on a copper grid for $1 \mathrm{~min}$ and then blotted with filter paper to remove excess solution. A drop of uranyl acetate solution $(0.5 \mathrm{wt} \%)$ was soaked on the same copper grid for $1.5 \mathrm{~min}$, and then blotted with filter paper. TEM observations were carried out on a Hitachi 7700 instrument operated at $120 \mathrm{kV}$.

Gel Permeation Chromatography $(G P C)$. The molecular weight and polydispersity of the samples were measured by gel permeation chromatography (GPC) using a Waters 1515 GPC instrument with dimethylformamide (DMF) as the mobile phase and Waters styragel HR1 and HR4 columns. The 
eluent used was HPLC grade DMF containing $10 \mathrm{mM} \mathrm{LiBr}$ and was filtered prior to use. The flow rate of DMF was $1.0 \mathrm{~mL} / \mathrm{min}$. Linear poly(methyl methacrylate) polymers with narrow molecular weight distributions were used as the standards to calibrate apparatus.

Fourier transform infrared (FTIR) spectroscopy. Each sample was ground up with $\mathrm{KBr}$ to form a fine power and compressed into a pallet. The FTIR spectra were recorded using a Nicolet 380 spectrometer.

Dynamic Light Scattering (DLS). Intensity-average hydrodynamic diameters of the dispersions $(0.1 \% \mathrm{v} / \mathrm{v})$ were obtained using a Brookhaven nanoparticle size-zeta potential analyzer.

Aqueous electrophoresis. Zeta potentials were determined as a function of solution $\mathrm{pH}$ using a Malvern Zetasizer Nano ZS instrument equipped with an auto-titrator for triblock nanoparticles diluted to approximately $0.3 \% \mathrm{w} / \mathrm{w}$. The solution $\mathrm{pH}$ was adjusted using $\mathrm{NaOH}$ or $\mathrm{HCl}$.

\section{Synthesis of PPEGMA15-CTA.}

PEGMA (30.0 g, 60 mmol), CDPA (1.38 g, 3.42 mmol), AIBN (0.1112 g, 0.68 mmol), 1,3,5trioxacyclohexane $(0.9 \mathrm{~g})$, and dioxane $(30.0 \mathrm{~g})$ were weighed into a $150 \mathrm{~mL}$ round bottom flask and purged with nitrogen for $30 \mathrm{~min}$. The flask was then immersed into a preheated oil bath at $70{ }^{\circ} \mathrm{C}$ for

$3.8 \mathrm{~h}$ (monomer conversion $=86 \%$ as determined by ${ }^{1} \mathrm{H}$ NMR). The reaction was then quenched by immersion in ice water and exposure to air. The product was precipitated by adding excess of n-hexane and washed several times with additional n-hexane. The precipitated product was then dried at $45{ }^{\circ} \mathrm{C}$ under vacuum overnight. The polymer was analyzed by DMF GPC with $M_{\mathrm{n}}=10.5 \mathrm{~kg} / \mathrm{mol}$ and $M_{\mathrm{w}} / M_{\mathrm{n}}$ $=1.13$ as determined by referring to poly(methyl methacrylate) standards.

\section{Synthesis of PPEGMA15-PHPMA275 diblock copolymer nanoparticles}

HPMA (3.0 g, 20.8 mmol), PPEGMA ${ }_{15}$-CTA (0.60 g, 0.076 mmol), and SPTP (7.8 g, $\left.25 \mu \mathrm{mol}\right)$ were weighed into a $25 \mathrm{~mL}$ round bottom flask. Then a certain amount of water $(12.0 \mathrm{~g})$ was added to dissolve all reagents. The reaction mixture was purged with nitrogen for $20 \mathrm{~min}$, and then irradiated by a visible light LED lamp $\left(405 \mathrm{~nm}, 0.45 \mathrm{~mW} / \mathrm{cm}^{2}\right)$ for $1 \mathrm{~h}$. The obtained product was then analyzed by ${ }^{1} \mathrm{H}$ NMR spectroscopy and TEM.

Synthesis of PPEGMA15-P(HPMA275-co-ALAM14) diblock copolymer nanoparticles 
HPMA (3.0 g, 20.8 mmol), PPEGMA $15-C T A(0.60$ g, 76 mmol), ALAM (0.1155 g, 1.04 mmol, 5 mol\% relative ratio of HPMA) and SPTP $(7.8 \mathrm{mg}, 25 \mu \mathrm{mol})$ were weighed into a $25 \mathrm{~mL}$ round bottom flask. Then a certain amount of water $(12.0 \mathrm{~g})$ was added to dissolve all reagents. The reaction mixture was purged with nitrogen for $20 \mathrm{~min}$, and then irradiated by a visible light LED lamp (405 nm, 0.45 $\mathrm{mW} / \mathrm{cm}^{2}$ ) for $1 \mathrm{~h}$. The obtained product was then analyzed by ${ }^{1} \mathrm{H}$ NMR spectroscopy and TEM.

\section{Synthesis of PPEGMA15-P(HPMA275-co-ALAM14)-PGlyMAn triblock copolymer nanoparticles}

In a typical experiment for the synthesis of POEGMA $\left.15-\mathrm{P}_{(\mathrm{HPMA}} \mathrm{H}_{25}-\mathrm{co}-\mathrm{ALAM}_{14}\right)-\mathrm{PGlyM}_{400}$ (solids content of $10 \% \mathrm{w} / \mathrm{w})$ : A solution of GlyMA (0.36 g, $2.5 \mathrm{mmol})$ in water $(5.08 \mathrm{~g})$ was added into the dispersion of PPEGMA $15-\mathrm{P}\left(\mathrm{HPMA}_{275}-\mathrm{co}-\mathrm{ALAM}_{14}\right)$ nanoparticles $(1.33 \mathrm{~g}$, containing $0.31 \mathrm{~g}$ $(6.4 \mu \mathrm{mol}) \mathrm{POEGMA}_{15}-\mathrm{P}\left(\mathrm{HPMA}_{275}\right.$-co-ALAM $\left.\left.{ }_{14}\right)\right)$. Then SPTP $(0.7 \mathrm{mg}, 2.13 \mu \mathrm{mol})$ was added into the reaction mixture. The reaction mixture was purged with nitrogen for $20 \mathrm{~min}$, and then irradiated by a visible light LED lamp (405 $\left.\mathrm{nm}, 0.45 \mathrm{~mW} / \mathrm{cm}^{2}\right)$ for $1 \mathrm{~h}$. The obtained product was then analyzed by ${ }^{1} \mathrm{H}$ NMR spectroscopy, DLS and TEM.

\section{Synthesis of PPEGMA15-PHPMA275-PGlyMAn triblock copolymer nanoparticles}

In a typical experiment for the synthesis of POEGMA $15-\mathrm{PHPMA}_{275}-\mathrm{PGlyMA}_{400}$ (solids content of $10 \% \mathrm{w} / \mathrm{w})$ : A solution of GlyMA $(0.36 \mathrm{~g}, 2.56 \mathrm{mmol})$ in water $(5.01 \mathrm{~g})$ was added into the dispersion of PPEGMA $15-$ PHPMA $_{275}$ nanoparticles $\left(1.32 \mathrm{~g}\right.$, containing $0.31 \mathrm{~g}(6.4 \mu \mathrm{mol})$ PPEGMA $_{15}-\mathrm{PHPMA}_{275}$ diblock copolymer nanoparticles. Then SPTP $(0.7 \mathrm{mg}, 3.17 \mu \mathrm{mol})$ was added into the reaction mixture. The reaction mixture was purged with nitrogen for $20 \mathrm{~min}$, and then irradiated by a visible light LED lamp (405 nm, $0.45 \mathrm{~mW} / \mathrm{cm}^{2}$ ) for $1 \mathrm{~h}$. The obtained product was then analyzed by ${ }^{1} \mathrm{H}$ NMR spectroscopy and TEM.

\section{Synthesis of PPEGMA15-P(HPMA275-co-ALAM14)-PHPMAn triblock copolymer nanoparticles}

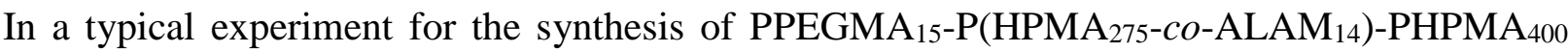
(solids content of 10\% w/w): A solution of HPMA (0.37 g, $2.53 \mathrm{mmol})$ in water $(5.08 \mathrm{~g})$ was added into the dispersion of PPEGMA $15-\mathrm{P}\left(\mathrm{HPMA}_{275}-\mathrm{co}-\mathrm{ALAM}_{14}\right)$ nanoparticles $(1.32 \mathrm{~g}$, containing $0.31 \mathrm{~g}$ $(6.33 \mu \mathrm{mol}) \mathrm{PPEGMA}_{15}-\mathrm{P}\left(\mathrm{HPMA}_{275}\right.$-co-ALAM $\left.\left.{ }_{14}\right)\right)$. Then SPTP $(0.7 \mathrm{mg}, 3.17 \mu \mathrm{mol})$ was added into the reaction mixture. The reaction mixture was purged with nitrogen for $20 \mathrm{~min}$, and then irradiated by a visible light LED lamp $\left(405 \mathrm{~nm}, 0.45 \mathrm{~mW} / \mathrm{cm}^{2}\right)$ for $1 \mathrm{~h}$. The obtained product was then analyzed by ${ }^{1} \mathrm{H}$ NMR spectroscopy, DLS and TEM. 
In a typical experiment for the synthesis of PPEGMA $15-\mathrm{PHPMA}_{275}-\mathrm{PHPMA}_{400}$ (solids content of $10 \% \mathrm{w} / \mathrm{w})$ : A solution of HPMA $(0.33 \mathrm{~g}, 2.26 \mathrm{mmol})$ in water $(4.46 \mathrm{~g})$ was added into the dispersion of POEGMA $15-$ PHPMA $_{275}$ nanoparticles $\left(1.17 \mathrm{~g}\right.$, containing $0.27 \mathrm{~g}(5.67 \mu \mathrm{mol})$ PPEGMA $_{15^{-}}$ PHPMA 275 . Then SPTP $(0.6 \mathrm{mg}, 1.89 \mu \mathrm{mol})$ was added into the reaction mixture. The reaction mixture was purged with nitrogen for $20 \mathrm{~min}$, and then irradiated by a visible light LED lamp (405 nm, 0.45 $\mathrm{mW} / \mathrm{cm}^{2}$ ) for $1 \mathrm{~h}$. The obtained product was then analyzed by ${ }^{1} \mathrm{H}$ NMR spectroscopy, and TEM.

Kinetic study of the synthesis of PPEGMA15-P(HPMA275-co-ALAM14)-PGlyMA400 triblock copolymer nanoparticles

A solution of GlyMA (0.64 g, $4.5 \mathrm{mmol})$ and DMF (0.033 g, as an internal standard) in water $(8.94 \mathrm{~g})$ was added into the dispersion of PPEGMA $15-\mathrm{P}\left(\mathrm{HPMA}_{275}-\mathrm{co}-\mathrm{ALAM}_{14}\right)$ nanoparticles $(2.34 \mathrm{~g}$, containing $0.55 \mathrm{~g}(11.25 \mu \mathrm{mol})$ PPEGMA $\left.15-\mathrm{P}\left(\mathrm{HPMA}_{275}-\mathrm{co}-\mathrm{ALAM}_{14}\right)\right)$. Then SPTP $(1.2 \mathrm{mg}, 3.75$ $\mu \mathrm{mol})$ was added into the reaction mixture. The reaction mixture was purged with nitrogen for 20 min, and then irradiated by a visible light LED lamp $\left(405 \mathrm{~nm}, 0.45 \mathrm{~mW} / \mathrm{cm}^{2}\right)$ for $1 \mathrm{~h}$. Samples were withdrawn at predetermined time intervals by syringes under nitrogen. The reaction was quenched by exposure to air and the addition of a small amount of hydroquinone. The samples were then analyzed by ${ }^{1} \mathrm{H}$ NMR spectroscopy.

Kinetic study of the synthesis of PPEGMA15-P(HPMA275-co-ALAM14)-PHPMA400 triblock copolymer nanoparticles

A solution of HPMA (0.65 g, $4.5 \mathrm{mmol})$ and DMF $(0.033 \mathrm{~g})$ in water $(9.03 \mathrm{~g})$ was added into the dispersion of PPEGMA $15-\mathrm{P}\left(\mathrm{HPMA}_{275}-\mathrm{Co}-\mathrm{ALAM}_{14}\right)$ nanoparticles $(2.34 \mathrm{~g}$, containing $0.55 \mathrm{~g}$ (11.26 $\mu \mathrm{mol}) \mathrm{PPEGMA}_{15}-\mathrm{P}\left(\mathrm{HPMA}_{275}\right.$-co-ALAM $\left.\left.{ }_{14}\right)\right)$. Then SPTP $(1.2 \mathrm{mg}, 3.75 \mu \mathrm{mol})$ was added into the reaction mixture. The reaction mixture was purged with nitrogen for $20 \mathrm{~min}$, and then irradiated by a visible light LED lamp (405 $\mathrm{nm}, 0.45 \mathrm{~mW} / \mathrm{cm}^{2}$ ) for $1 \mathrm{~h}$. Samples were withdrawn at predetermined time intervals by syringes under nitrogen. The reaction was quenched by exposure to air and the addition of a small amount of hydroquinone. The samples were then analyzed by ${ }^{1} \mathrm{H}$ NMR spectroscopy.

\section{Synthesis of PPEGMA15-P(HPMA275-co-ALAM14)-PMMAn triblock copolymer nanoparticles}

In a typical experiment for the synthesis of PPEGMA $15-\mathrm{P}\left(\mathrm{HPMA}_{275}-\mathrm{co}-\mathrm{ALAM}_{14}\right)-\mathrm{PMMA}_{400}$ (solids content of 10\% w/w): A solution of MMA (0.29 g, $2.9 \mathrm{mmol})$ dissolved in water (4.67 $\mathrm{g}$ ) was added into the dispersion of PPEGMA $15-\mathrm{P}\left(\mathrm{HPMA}_{275}\right.$-co-ALAM $\left.{ }_{14}\right)$ nanoparticles $(1.51 \mathrm{~g}$, containing 
$0.36 \mathrm{~g}(7.26 \mu \mathrm{mol})$ PPEGMA $\left._{15}-\mathrm{P}\left(\mathrm{HPMA}_{275}-\mathrm{co}-\mathrm{ALAM}_{14}\right)\right)$. Then $\operatorname{SPTP}(0.8 \mathrm{mg}, 2.58 \mu \mathrm{mol})$ was added into the reaction mixture. The reaction mixture was purged with nitrogen for $20 \mathrm{~min}$, and then irradiated by a visible light LED lamp (405 nm, $\left.0.45 \mathrm{~mW} / \mathrm{cm}^{2}\right)$ for $1 \mathrm{~h}$. The obtained product was then analyzed by ${ }^{1} \mathrm{H}$ NMR spectroscopy and TEM.

\section{Synthesis of PPEGMA15-P(HPMA275-co-ALAM14)-PBzMAn triblock copolymer nanoparticles}

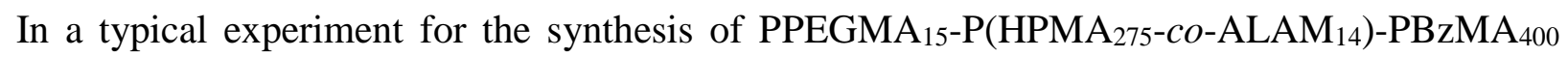
( solids content of $10 \% \mathrm{w} / \mathrm{w})$ : A solution of BzMA $(0.42 \mathrm{~g}, 2.40 \mathrm{mmol})$ in water $(5.50 \mathrm{~g})$ was added into the dispersion of PPEGMA $15-\mathrm{P}\left(\mathrm{HPMA}_{275}-\mathrm{co}-\mathrm{ALAM}_{14}\right)$ nanoparticles $(1.24 \mathrm{~g}$, containing $0.29 \mathrm{~g}$ $\left.(6.0 \mu \mathrm{mol}) \mathrm{PPEGMA}_{15}-\mathrm{P}\left(\mathrm{HPMA}_{275}-\mathrm{co}-\mathrm{ALAM}_{14}\right)\right)$. Then SPTP $(0.6 \mathrm{mg}, 1.9 \mu \mathrm{mol})$ was added into the reaction mixture. The reaction mixture was put into a pre-heated water bath $\left(40{ }^{\circ} \mathrm{C}\right.$ or $\left.70{ }^{\circ} \mathrm{C}\right)$, purged with nitrogen for $20 \mathrm{~min}$, and then irradiated by a visible light LED lamp (405 nm, $0.45 \mathrm{~mW} / \mathrm{cm}^{2}$ ) for $1 \mathrm{~h}$. The obtained product was then analyzed by ${ }^{1} \mathrm{H}$ NMR spectroscopy and TEM.

\section{Synthesis of PPEGMA15-P(HPMA275-co-ALAM14)-PtBAn triblock copolymer nanoparticles}

In a typical experiment for the synthesis of $\mathrm{PPEGMA}_{15}-\mathrm{P}\left(\mathrm{HPMA}_{275}-\mathrm{co}-\mathrm{ALAM}_{14}\right)-\mathrm{P} \mathrm{BA} 400$ (solids content of $10 \% \mathrm{w} / \mathrm{w})$ : A solution of $t \mathrm{BA}(0.39 \mathrm{~g}, 3.0 \mathrm{mmol})$ in water $(5.60 \mathrm{~g})$ was added into the dispersion of PPEGMA $15-\mathrm{P}\left(\mathrm{HPMA}_{275}\right.$-Co-ALAM $\left.{ }_{14}\right)$ nanoparticles $(1.56 \mathrm{~g}$, containing $0.37 \mathrm{~g}$ (7.51 $\mu$ mol) PPEGMA $15-\mathrm{P}\left(\mathrm{HPMA}_{275}\right.$-co-ALAM $\left.\left.{ }_{14}\right)\right)$. Then SPTP $(0.8 \mathrm{mg}, 2.58 \mu \mathrm{mol})$ was added into the reaction mixture. The reaction mixture was purged with nitrogen for $20 \mathrm{~min}$, and then irradiated by a visible light LED lamp (405 nm, $0.45 \mathrm{~mW} / \mathrm{cm}^{2}$ ) for $1 \mathrm{~h}$. The obtained product was then analyzed by ${ }^{1} \mathrm{H}$ NMR spectroscopy and TEM.

\section{Synthesis of PPEGMA15-P(HPMA275-co-ALAM14)-PNIPAMn triblock copolymer nanoparticles}

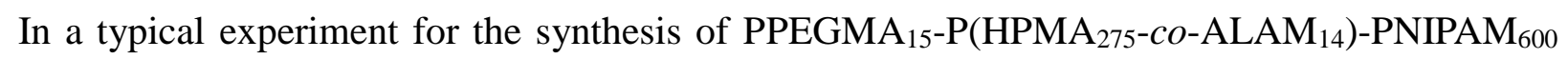
(solids content of $10 \% \mathrm{w} / \mathrm{w})$ : A solution of NIPAM $(0.46 \mathrm{~g}, 4.08 \mathrm{mmol})$ in water $(6.08 \mathrm{~g})$ was added into the dispersion of PPEGMA $15-\mathrm{P}\left(\mathrm{HPMA}_{275}-\mathrm{co}-\mathrm{ALAM}_{14}\right)$ nanoparticles $(1.41 \mathrm{~g}$, containing $0.33 \mathrm{~g}$ $\left.(6.8 \mu \mathrm{mol}) \mathrm{PPEGMA}_{15}-\mathrm{P}\left(\mathrm{HPMA}_{275}-\mathrm{co}-\mathrm{ALAM}_{14}\right)\right)$. Then SPTP $(0.7 \mathrm{mg}, 2.26 \mu \mathrm{mol})$ was added into the reaction mixture. The reaction mixture was immersed into a pre-heated water bath $\left(35^{\circ} \mathrm{C}\right)$, purged with nitrogen for $20 \mathrm{~min}$, and then irradiated by a visible light LED lamp (405 nm, $0.45 \mathrm{~mW} / \mathrm{cm}^{2}$ ) for $1 \mathrm{~h}$. The obtained product was then analyzed by ${ }^{1} \mathrm{H}$ NMR spectroscopy and TEM.

Synthesis of PPEGMA15-P(HPMA275-co-ALAM14)-P(NIPAMn-co-ALAMm) triblock copolymer nanoparticles 
In a typical experiment for the synthesis of PPEGMA $15-\mathrm{P}\left(\mathrm{HPMA}_{275}-\mathrm{co}-\mathrm{ALAM}_{14}\right)-\mathrm{P}\left(\mathrm{NIPAM}_{600}-\right.$ co-ALAM 30 ) (solids content of $10 \% \mathrm{w} / \mathrm{w})$ : A solution of NIPAM (0.41 g, $3.61 \mathrm{mmol})$ and ALAM (0.02 $\mathrm{g}, 0.18 \mathrm{mmol}, 5 \mathrm{~mol} \%$ relative ratio of NIPAM) in water $(5.57 \mathrm{~g})$ was added into the dispersion of PPEGMA $_{15}-\mathrm{P}\left(\mathrm{HPMA}_{275}\right.$-co-ALAM $\left.{ }_{14}\right)$ nanoparticles $(1.25 \mathrm{~g}$, containing $0.30 \mathrm{~g}(6.02 \mu \mathrm{mol})$ PPEGMA $_{15}-\mathrm{P}\left(\mathrm{HPMA}_{275}\right.$-co-ALAM $\left.\left.{ }_{14}\right)\right)$. Then SPTP $(0.6 \mathrm{mg}, 1.94 \mu \mathrm{mol})$ was added into the reaction mixture. The reaction mixture was put into a pre-heated water bath $\left(35^{\circ} \mathrm{C}\right)$, purged with nitrogen for $20 \mathrm{~min}$, and then irradiated by a visible light LED lamp (405 nm, $0.45 \mathrm{~mW} / \mathrm{cm}^{2}$ ) for $1 \mathrm{~h}$. The obtained product was then analyzed by ${ }^{1} \mathrm{H}$ NMR spectroscopy and TEM.

Post-polymerization modification of PPEGMA15-P(HPMA275-co-ALAM14)-PGlyMA400 triblock copolymer nanoparticles using EDA or 3-MPA

The PPEGMA $15-\mathrm{P}\left(\mathrm{HPMA}_{275}-\mathrm{co}-\mathrm{ALAM}_{14}\right)-\mathrm{PGlyMA}_{400}$ triblock copolymer nanoparticles was derivatized with EDA using the following protocol: a $5 \% \mathrm{w} / \mathrm{w}$ aqueous solution of PPEGMA $15^{-}$ P(HPMA $275-c o-A L A M 14)-P G l y M A_{400}(6.0$ g polymer, 1.13 mmol epoxy groups) and EDA (136 mg, $2.26 \mathrm{mmol}$, EDA/epoxy molar ratio $=2$ ) were weighed into a $10 \mathrm{~mL}$ vial. The reaction mixture was adjusted to approximately $\mathrm{pH} 10$ using $\mathrm{KOH}$ and then stirred for $24 \mathrm{~h}$ at $60{ }^{\circ} \mathrm{C}$. The resulting derivatized triblock copolymer nanoparticles was purified by several centrifugation-redispersion cycles with water to remove excess EDA. The same protocol was used for the reaction of 3-MPA(3MPA/epoxy molar ratio $=5$ ). The obtained products were then analyzed by TEM, FTIR and aqueous electrophoresis. 


\section{ADDITIONAL RESULTS}

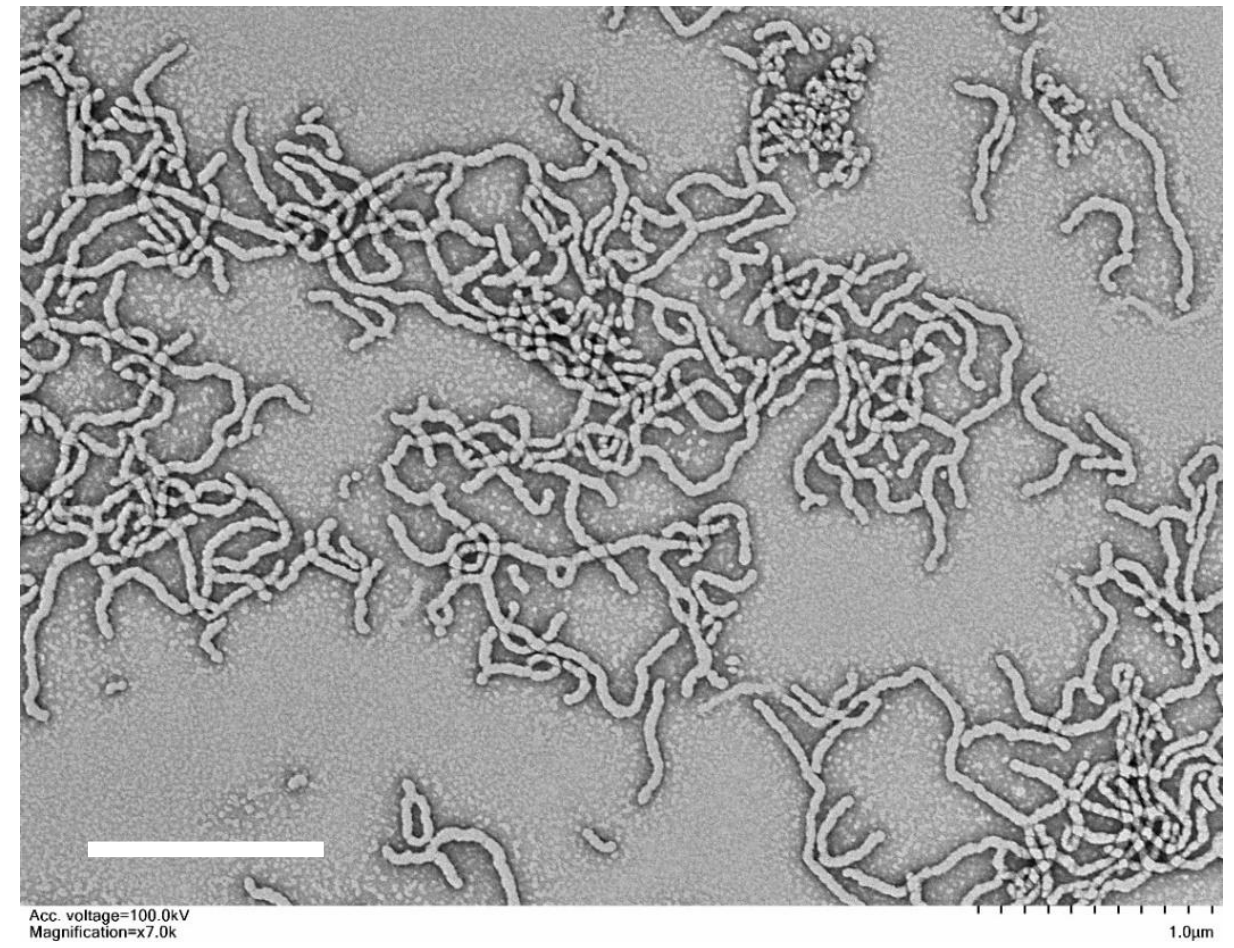

Figure S1. TEM image of PPEGMA $15-\mathrm{PHPMA}_{275}$ diblock copolymer nano-objects prepared by aqueous photo-PISA of HPMA $(20 \% \mathrm{w} / \mathrm{w})$. Scale bar: $1 \mu \mathrm{m}$.

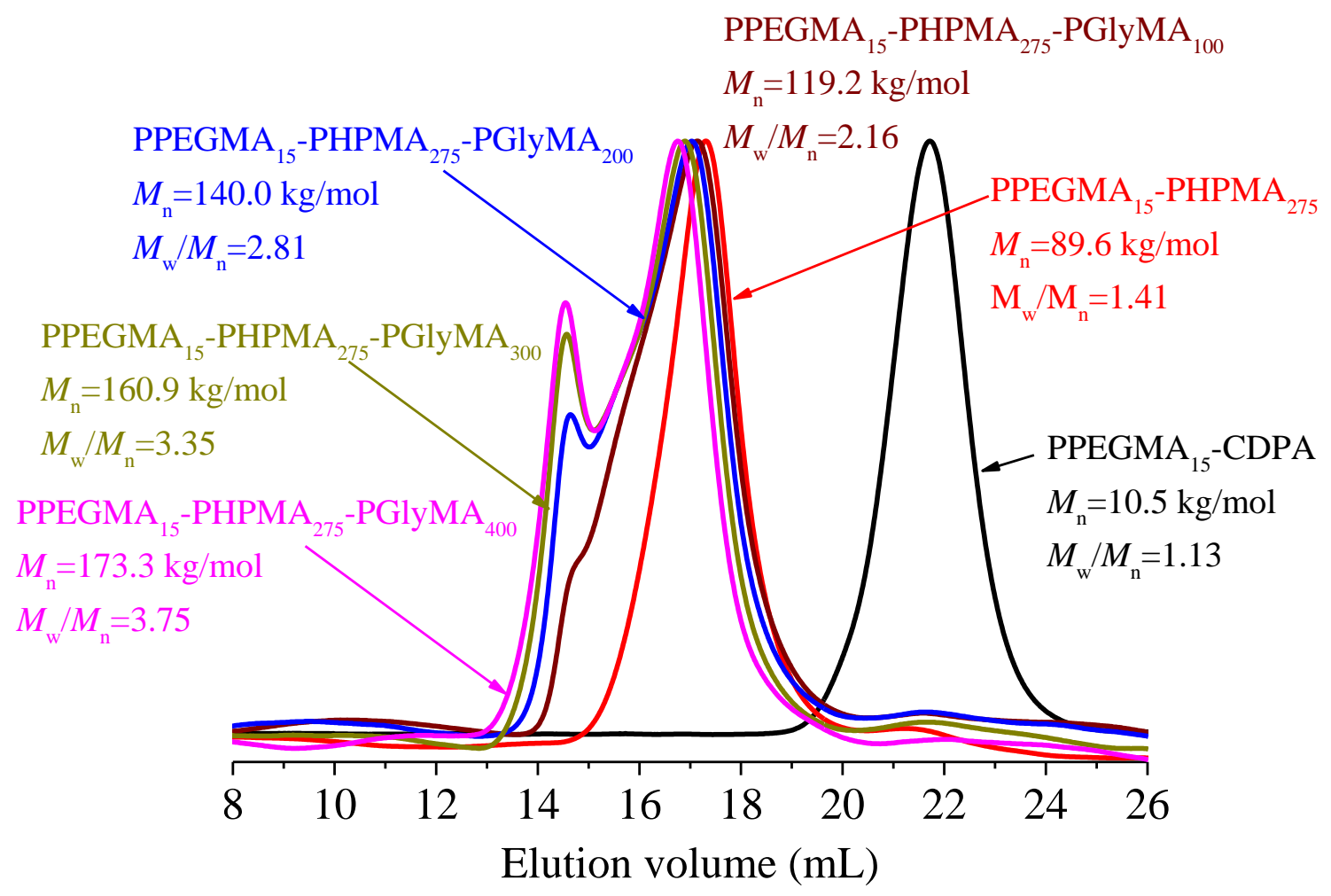

Figure S2. GPC traces of PPEGMA $15-C D P A, P_{15}$ PMA $_{15}-\mathrm{PHPMA}_{275}$, and PPEGMA $15-\mathrm{PHPMA}_{275}$ - 
PGlyMAn $_{n}(\mathrm{n}=100,200,300,400)$.

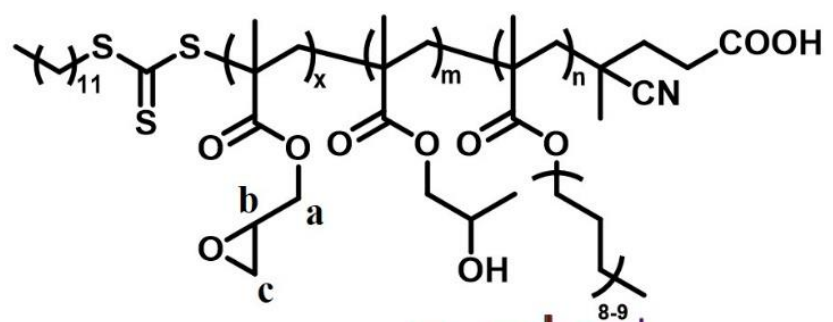

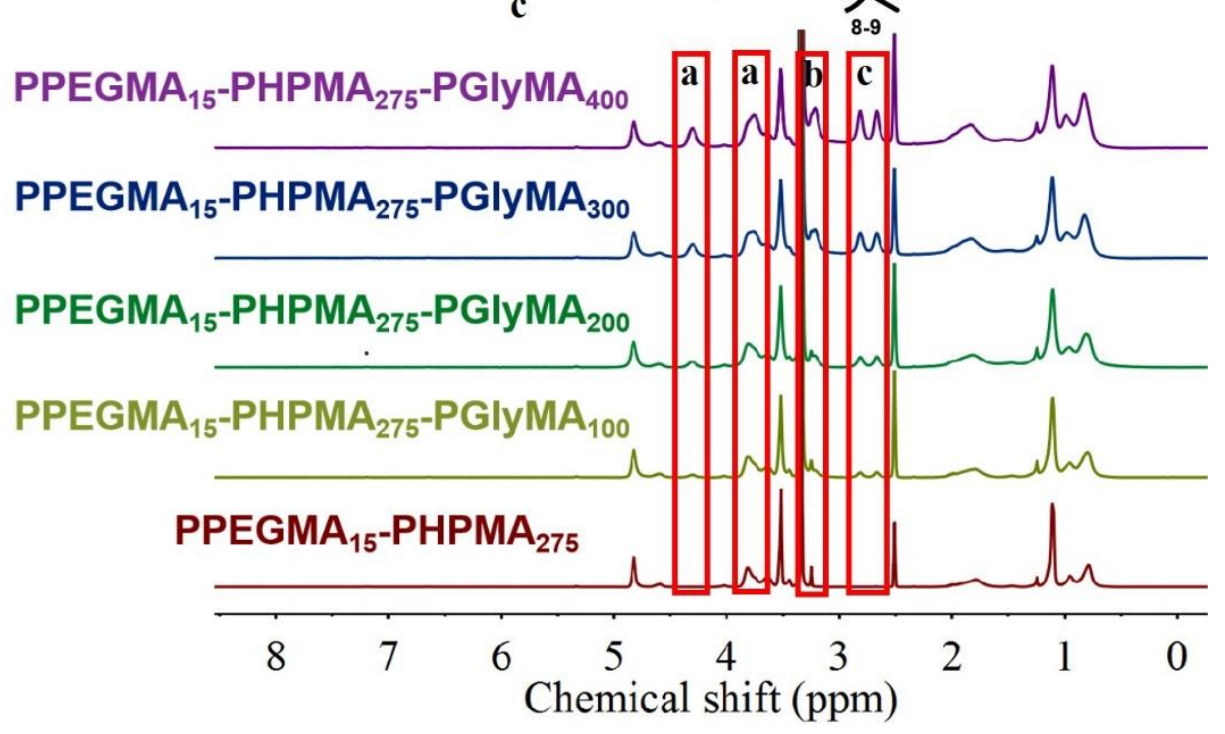

Figure S3. ${ }^{1} \mathrm{H}$ NMR spectra of PPEGMA $15-\mathrm{PHPMA}_{275}$ and PPEGMA $15-\mathrm{PHPMA}_{275}-\mathrm{PGlyMA}_{\mathrm{n}}(\mathrm{n}=$ $100,200,300,400)$.

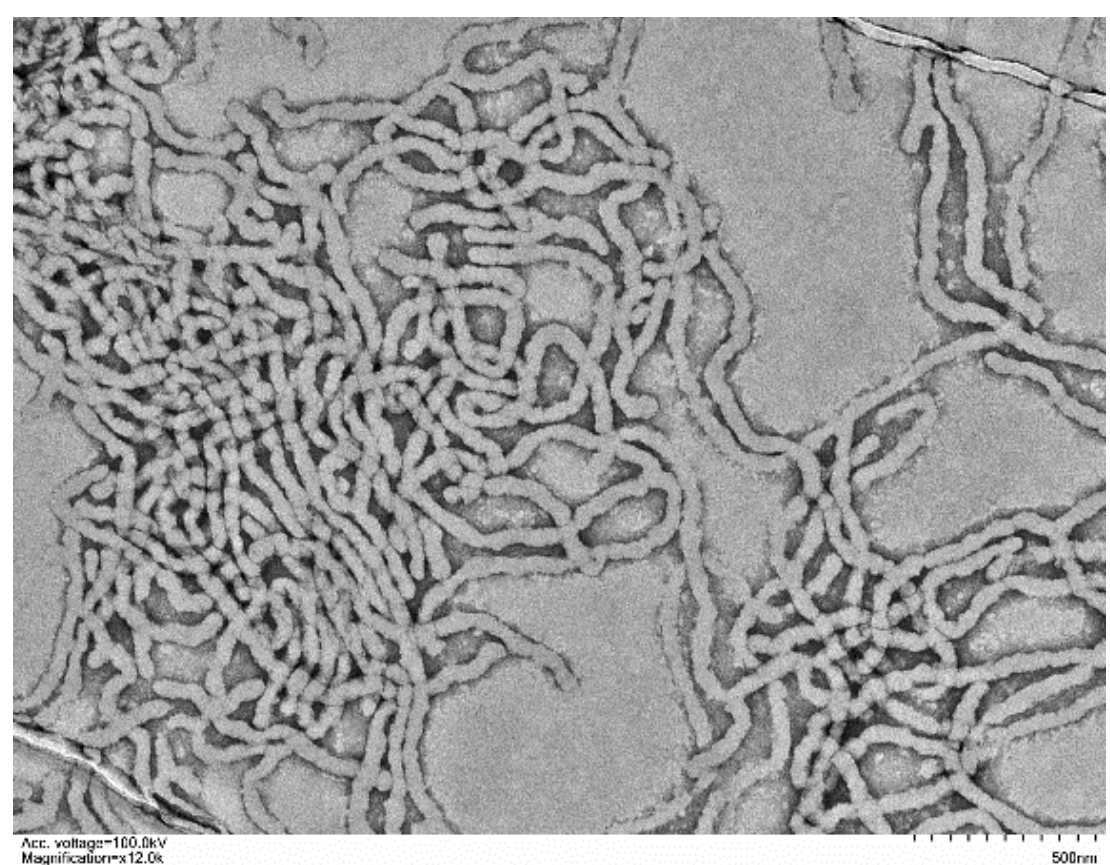

Figure S4. TEM image of PPEGMA $15-\mathrm{P}\left(\mathrm{HPMA}_{275}-\mathrm{co}-\mathrm{ALAM}_{14}\right)$ diblock copolymer nano-objects prepared by aqueous photo-PISA (20\% w/w HPMA). Scale bar: $0.5 \mu \mathrm{m}$. 


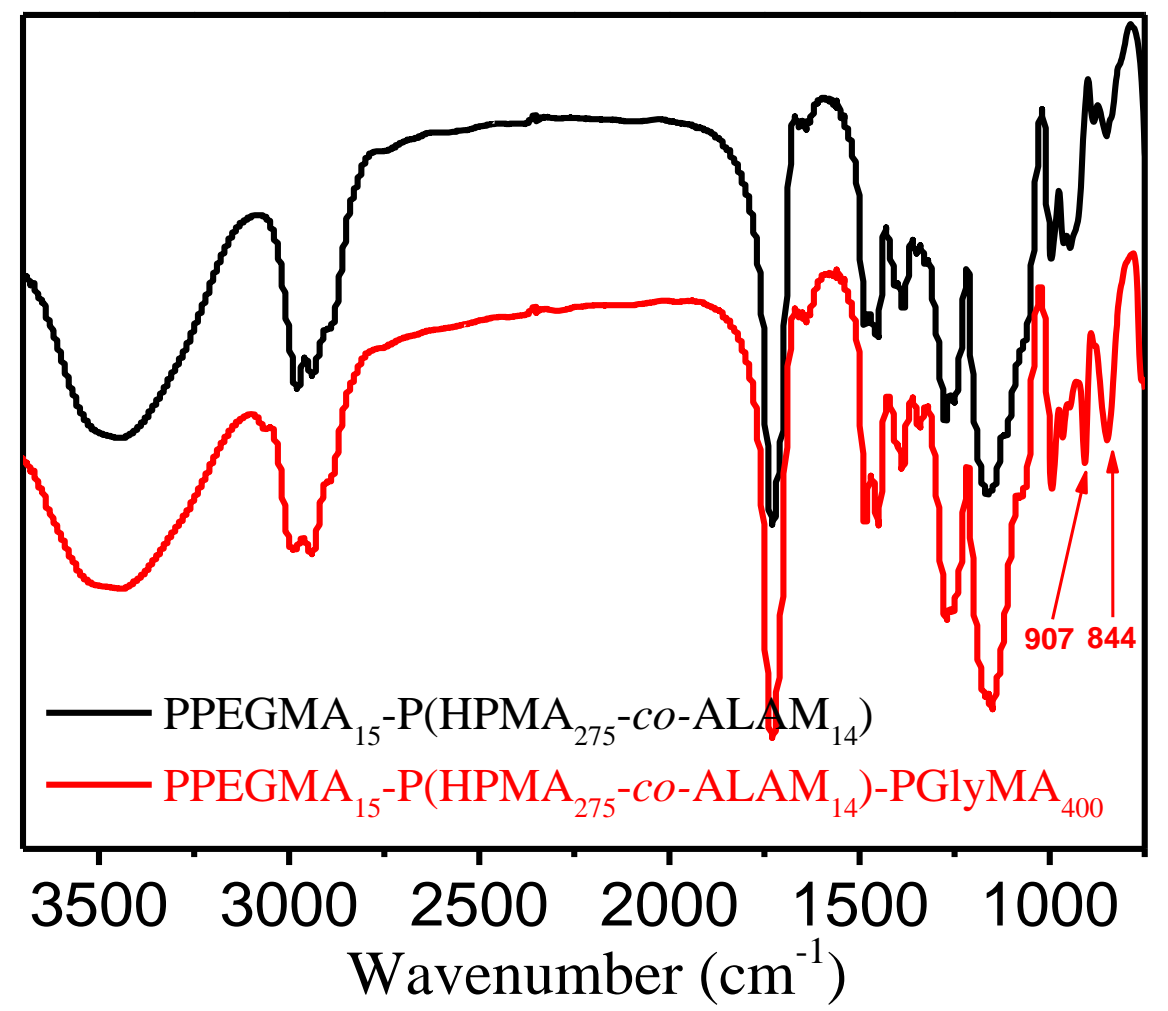

Figure S5. FT-IR spectra of PPEGMA $15-\mathrm{P}\left(\mathrm{HPMA}_{275}-\mathrm{co}-\mathrm{ALAM}_{14}\right)$ and $\mathrm{PPEGMA}_{15}-\mathrm{P}\left(\mathrm{HPMA}_{275}-\mathrm{co}-\right.$ ALAM $\left._{14}\right)$-PGlyMA400

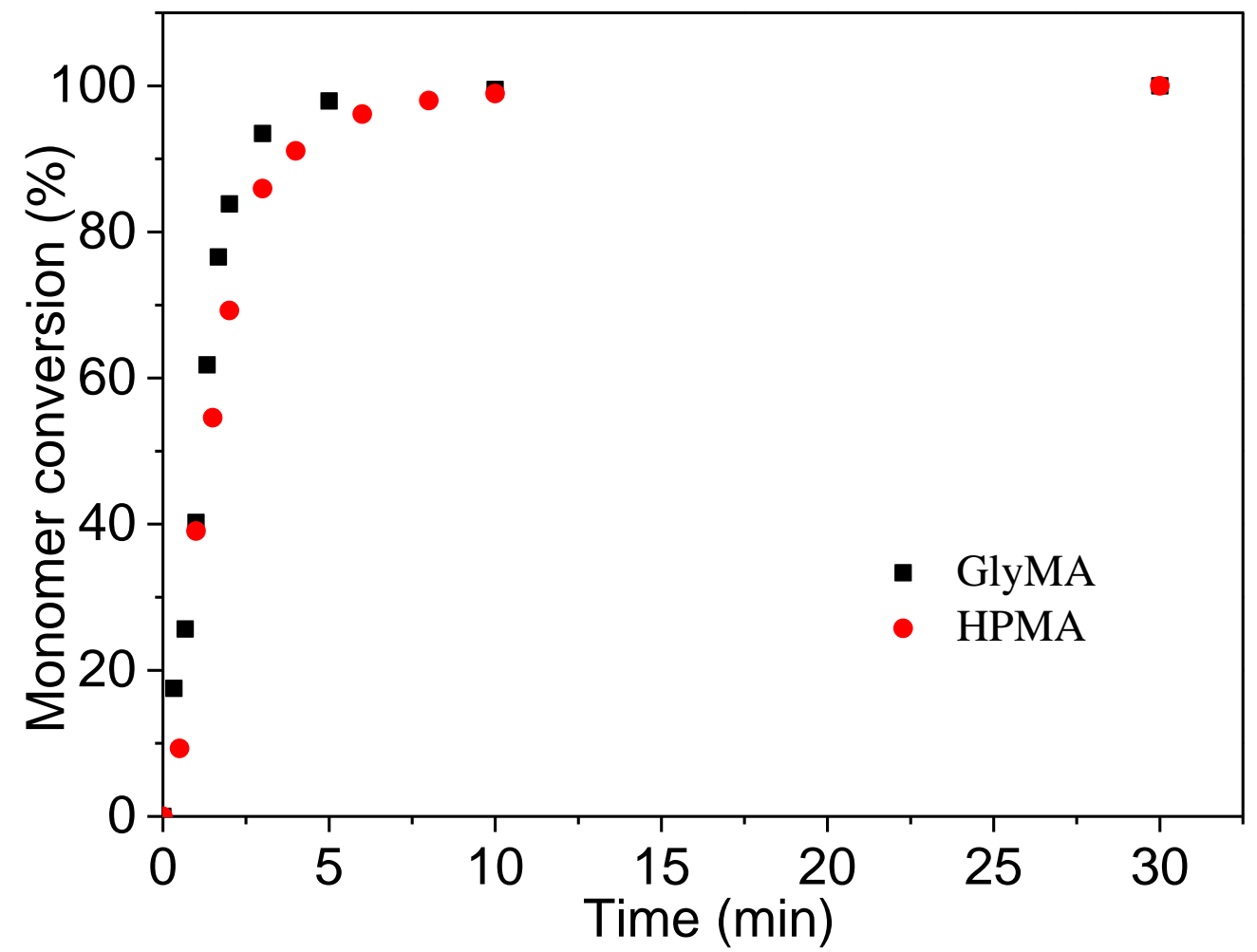

Figure S6. Polymerization kinetics for aqueous seeded photo-PISA of GlyMA or HPMA using PPEGMA $_{15}-\mathrm{P}\left(\mathrm{HPMA}_{275}\right.$-co-ALAM $\left.{ }_{14}\right)$ cylindrical micelles as seeds (target DP of 400). 

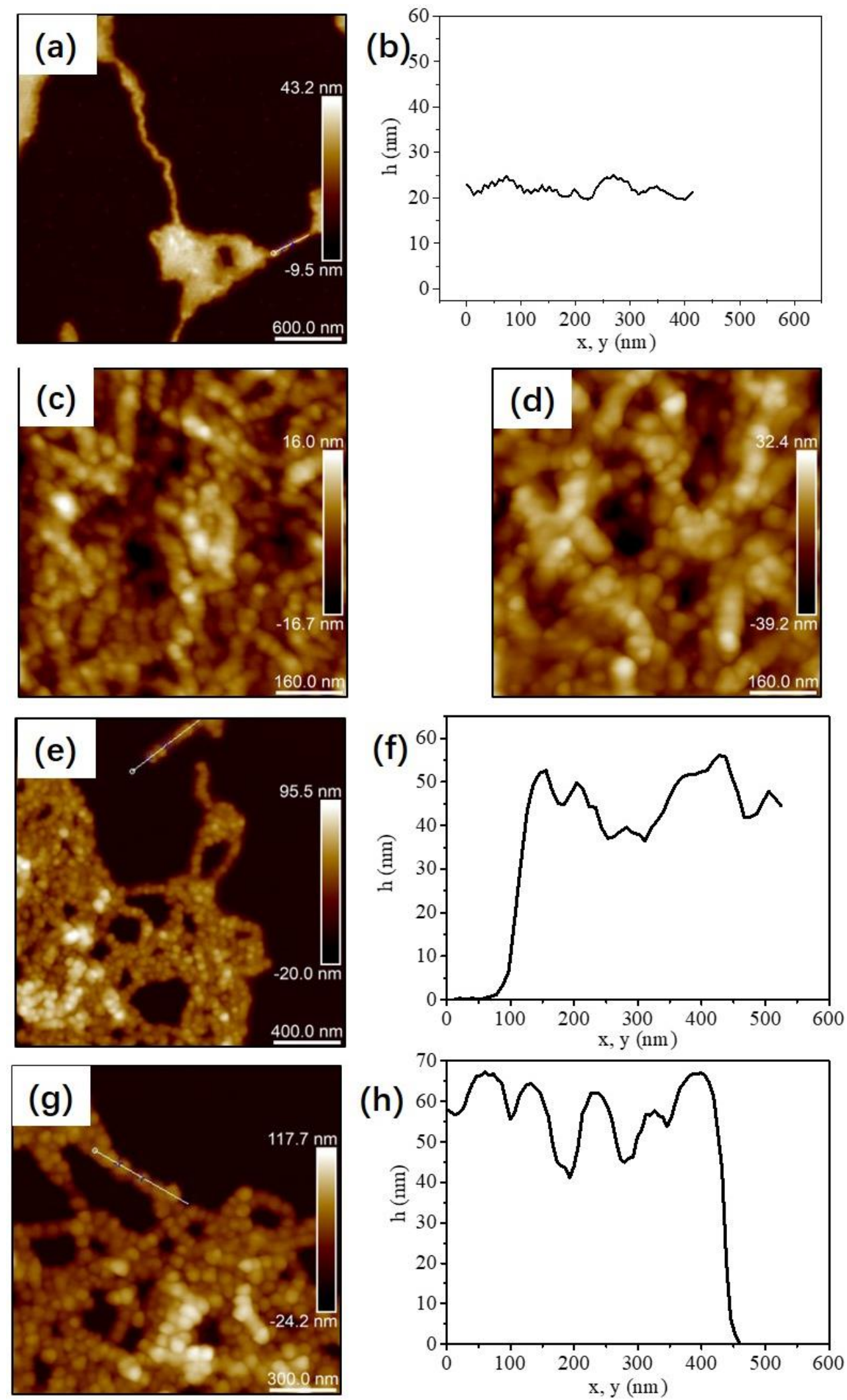

Figure S7. AFM images of PPEGMA $15-\mathrm{P}\left(\mathrm{HPMA}_{275}-\mathrm{co}-\mathrm{ALAM}_{14}\right)-\mathrm{PGlyMA}_{n}$ cylindrical micelles: (a) $\mathrm{n}=0$, (c) $n=100$, (d) $n=200$, (e) $n=300,(g) n=400$. (b) Height profile along with the white line shown in Figure S7a. (f) Height profile along with the white line shown in Figure S7e. (h) Height profile along with the white line shown in Figure S7g. 


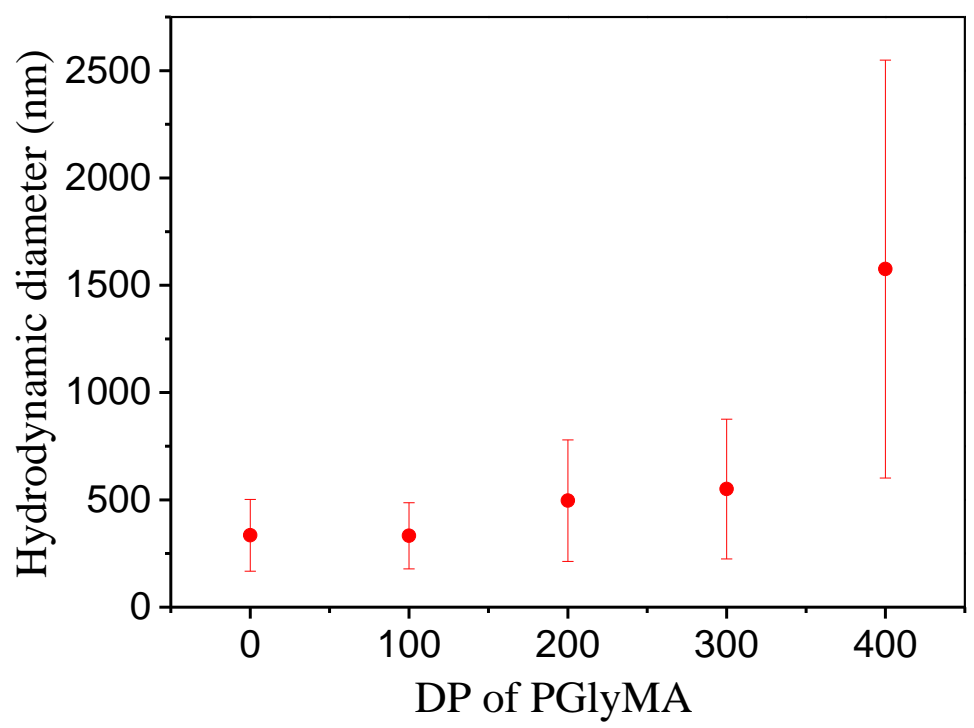

Figure S8. DLS results of PPEGMA $15-\mathrm{P}\left(\mathrm{HPMA}_{275}-\mathrm{co}-\mathrm{ALAM}_{14}\right)-\mathrm{PGlyMA}_{\mathrm{n}}$ cylindrical micelles. Error bars indicate the particle size distribution rather than experimental error.
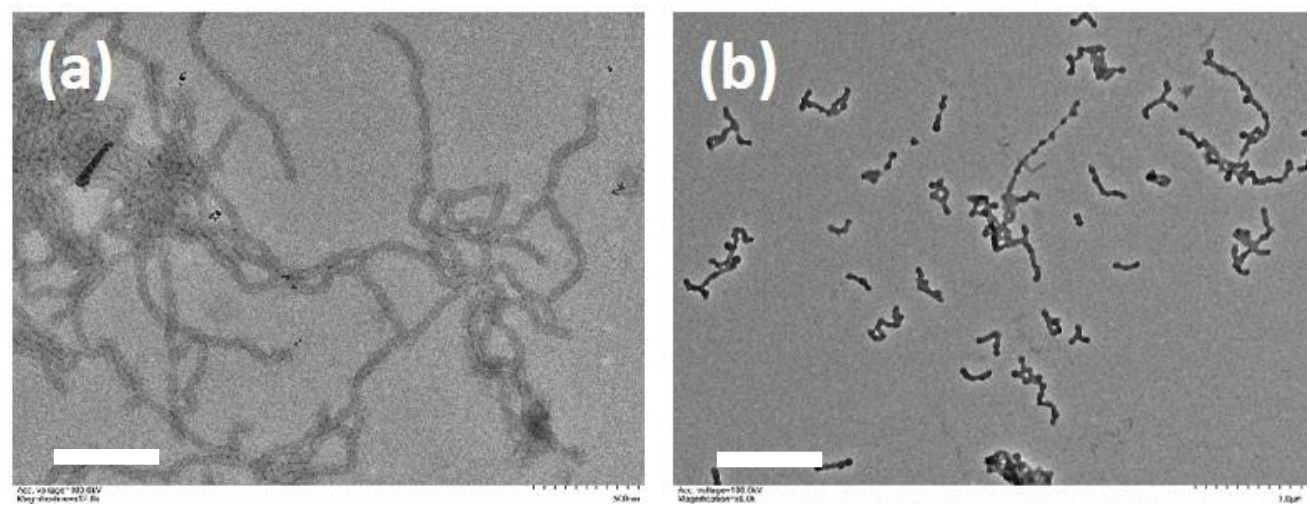

Figure S9. (a) TEM image PPEGMA $15-\mathrm{P}\left(\mathrm{HPMA}_{275}-\mathrm{co}-\mathrm{ALAM}_{8.3}\right)$ diblock copolymer nano-objects prepared by aqueous photo-PISA. Scale bar: $0.5 \mu \mathrm{m}$. (b) TEM image of PPEGMA $15-\mathrm{P}_{(\mathrm{HPMA}} \mathrm{H}_{25}-\mathrm{co}-$

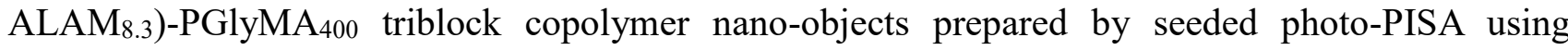
PPEGMA $_{15}-\mathrm{P}\left(\mathrm{HPMA}_{275}-\mathrm{co}-\mathrm{ALAM}_{8.3}\right)$ cylindrical micelles as seeds. Scale bar: $1 \mu \mathrm{m}$. 

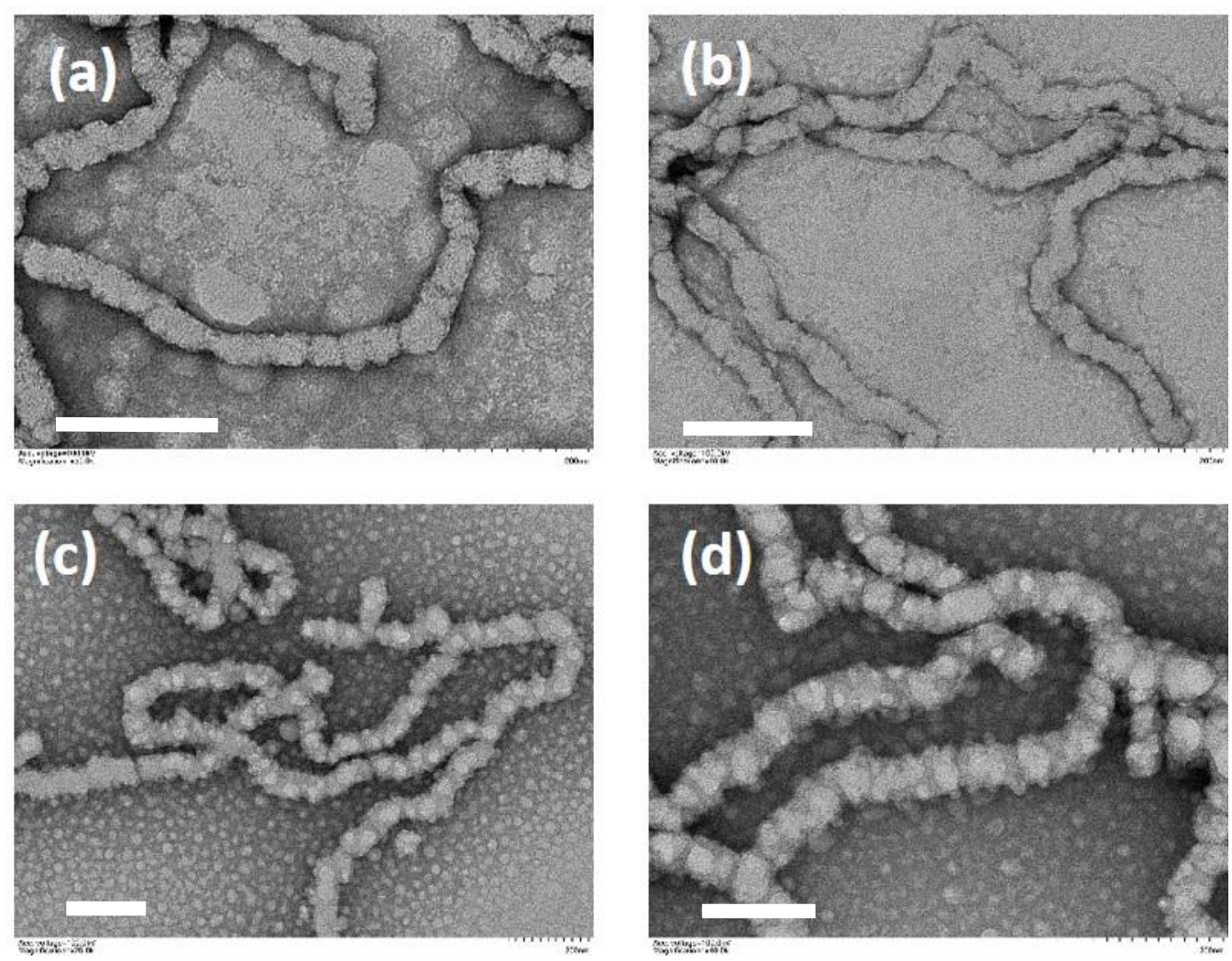

Figure S10. TEM images of PPEGMA $15-\mathrm{P}\left(\mathrm{HPMA}_{275}-\mathrm{co}-\mathrm{ALAM}_{14}\right)-\mathrm{PMMA}_{n}$ cylindrical micelles prepared by aqueous seeded photo-PISA of MMA: (a) $n=100$, (b) $n=200$, (c) $n=300$, (d) $n=400$. Scale bars: $0.2 \mu \mathrm{m}$. 

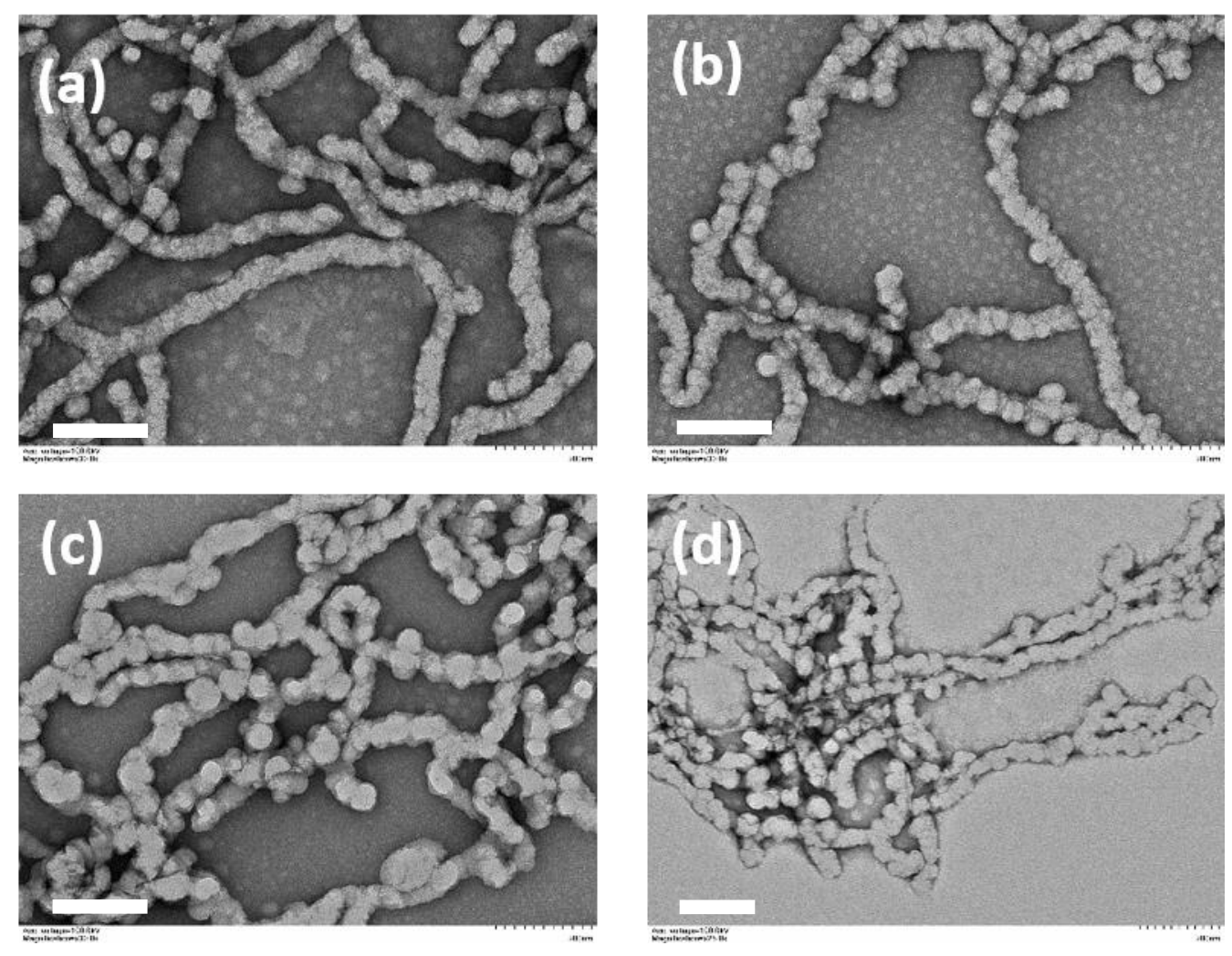

Figure S11. TEM images of PPEGMA $15-\mathrm{P}\left(\mathrm{HPMA}_{275}-\mathrm{co}-\mathrm{ALAM}_{14}\right)-\mathrm{P} t \mathrm{BA}_{\mathrm{n}}$ cylindrical micelles prepared by aqueous seeded photo-PISA of $t$ BA: (a) $n=100$, (b) $n=200$, (c) $n=300$, (d) $n=400$. Scale bars: $0.2 \mu \mathrm{m}$. 

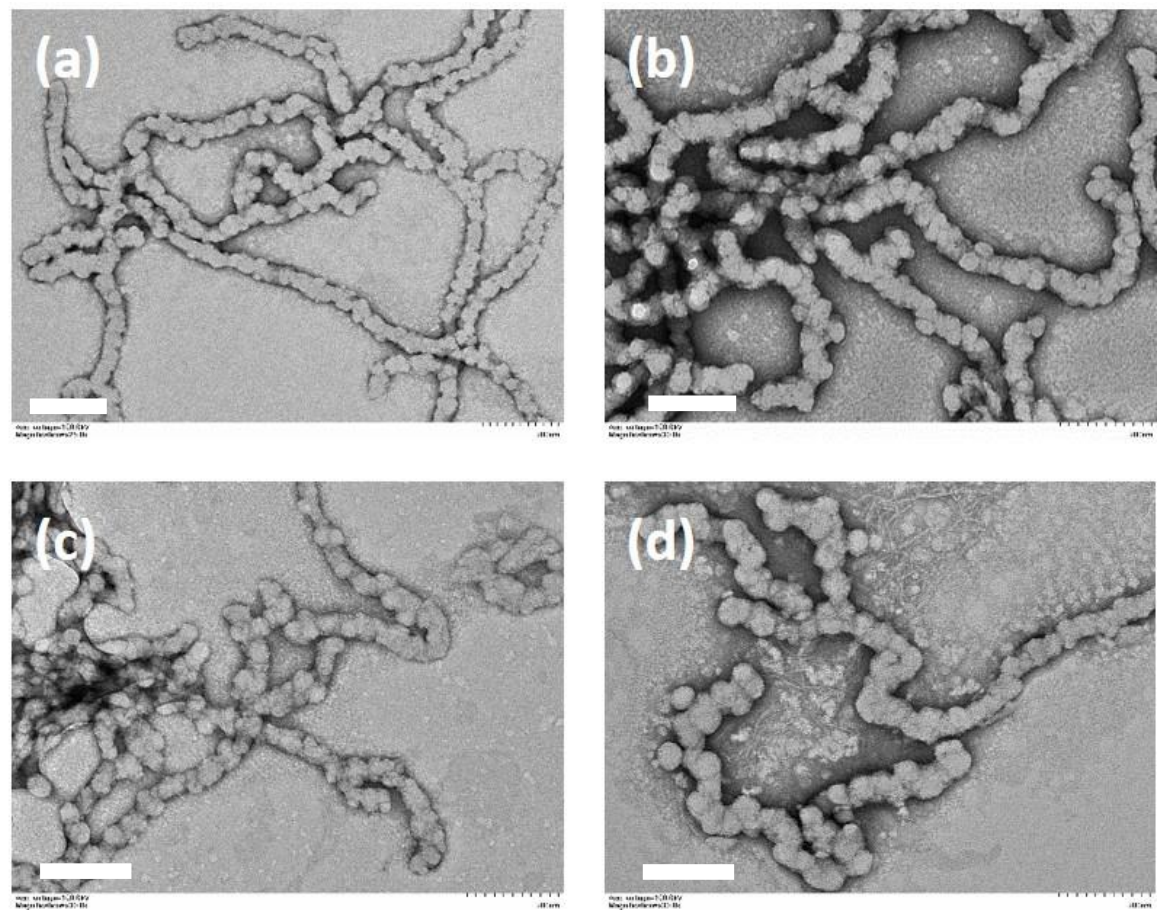

Figure S12. TEM images of PPEGMA $15-\mathrm{P}\left(\mathrm{HPMA}_{275}-\mathrm{co}-\mathrm{ALAM}_{14}\right)-\mathrm{PBzMA}_{\mathrm{n}}$ cylindrical micelles prepared by aqueous seeded photo-PISA of BzMA at $40{ }^{\circ} \mathrm{C}$ : (a) $n=100$, (b) $n=200$, (c) $n=300$, (d) $\mathrm{n}=400$. Scale bars: $0.2 \mu \mathrm{m}$.
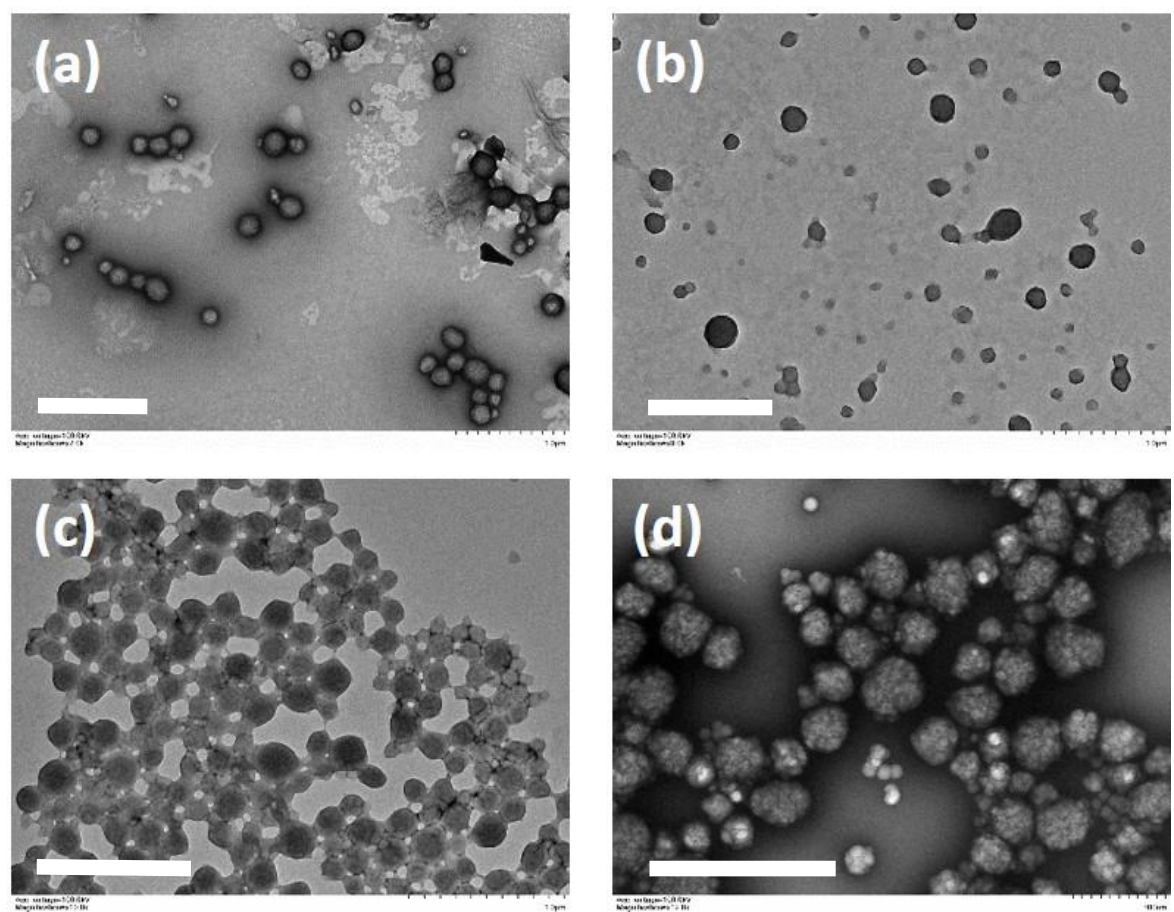

Figure S13. TEM images of PPEGMA $15-\mathrm{P}\left(\mathrm{HPMA}_{275}-\mathrm{co}-\mathrm{ALAM}_{14}\right)-\mathrm{PBzMA}_{n}$ cylindrical micelles prepared by aqueous seeded photo-PISA of BzMA at $70{ }^{\circ} \mathrm{C}$ : (a) $n=100$, (b) $n=200$, (c) $n=300$, (d) $\mathrm{n}=400$. Scale bars: $1 \mu \mathrm{m}$. 


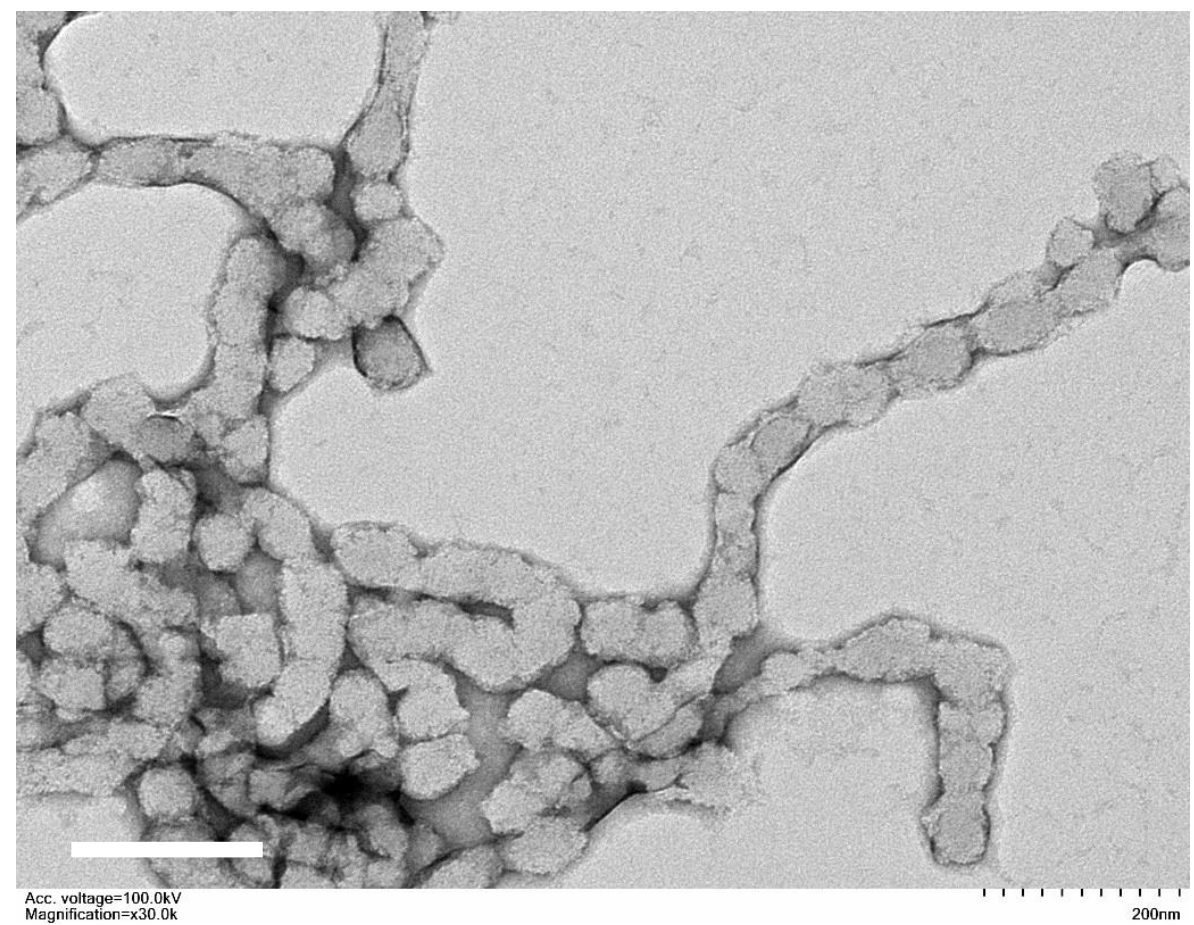

Figure S14. TEM image of PPEGMA $15-\mathrm{P}\left(\mathrm{HPMA}_{275}-\mathrm{co}-\mathrm{ALAM}_{14}\right)-\mathrm{PGlyMA}_{400}$ patchy cylindrical micelles dispersed in 1\% w/w SDS for $24 \mathrm{~h}$ and purified by three centrifugation-redispersion cycles. Scale bar: $0.2 \mu \mathrm{m}$.

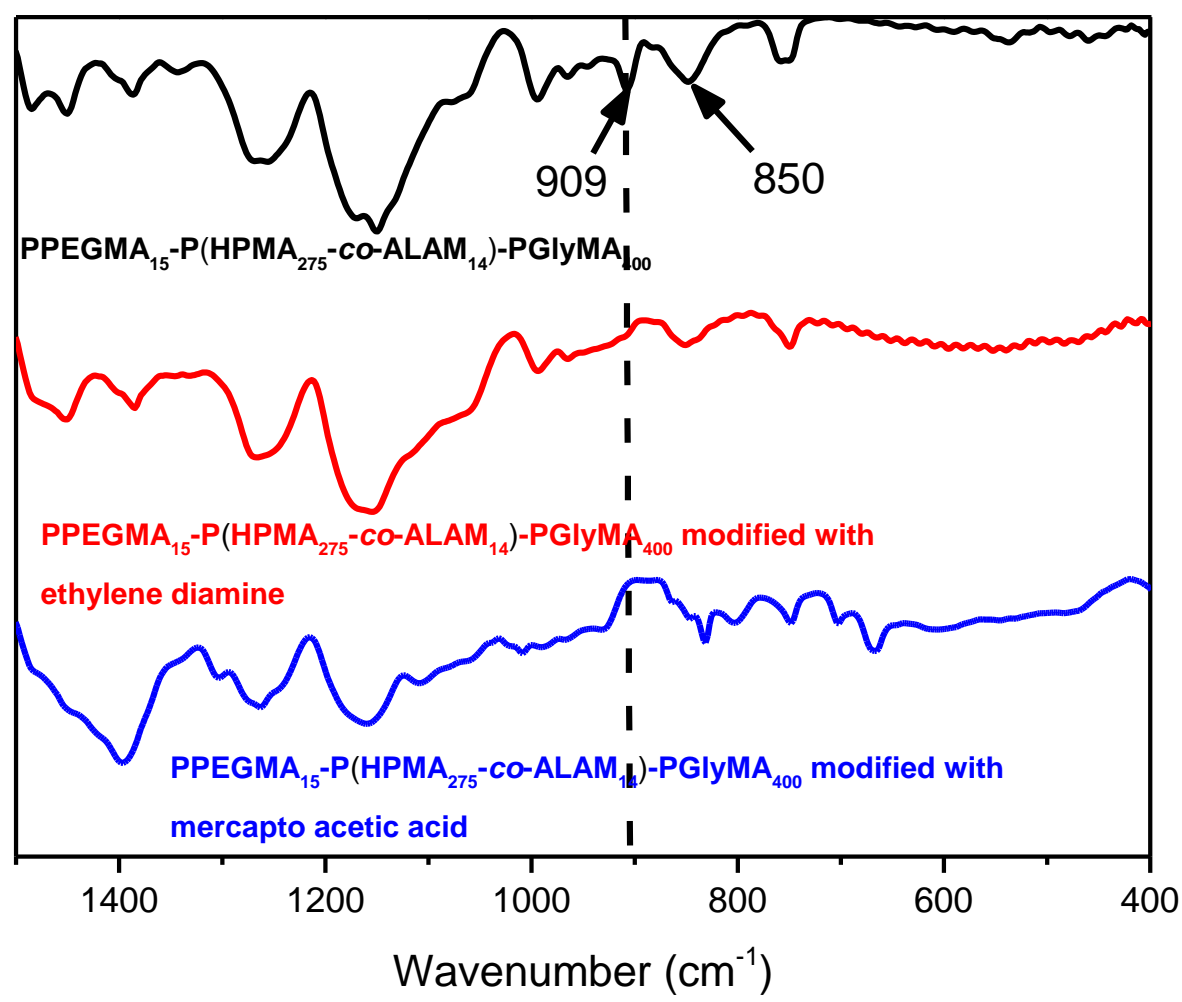

Figure S15. FT-IR spectra of PPEGMA $15-\mathrm{P}\left(\mathrm{HPMA}_{275}-\mathrm{co}-\mathrm{ALAM}_{14}\right)-\mathrm{PGlyMA}_{400}$ patchy cylindrical micelles before and after modification with ethylene diamine and mercapto acetic acid. 


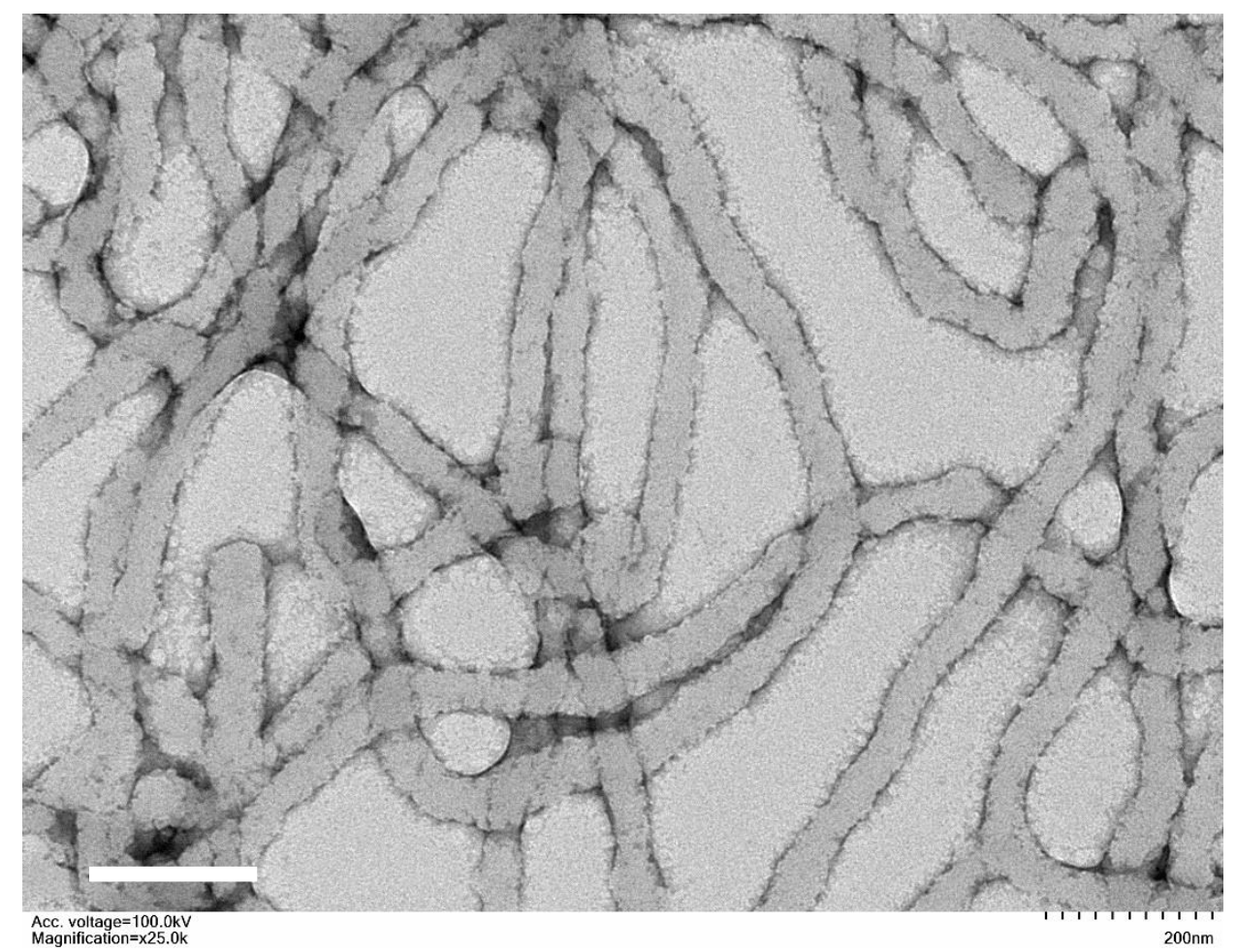

Figure S16. TEM image of PPEGMA $15-\mathrm{P}\left(\mathrm{HPMA}_{275}-\mathrm{co}-\mathrm{ALAM}_{14}\right)-\mathrm{PNIPAM}_{300}$ cylindrical micelles prepared at $35{ }^{\circ} \mathrm{C}$. The sample preparation for TEM measurement was maintained at $35{ }^{\circ} \mathrm{C}$ without any cooling procedure.
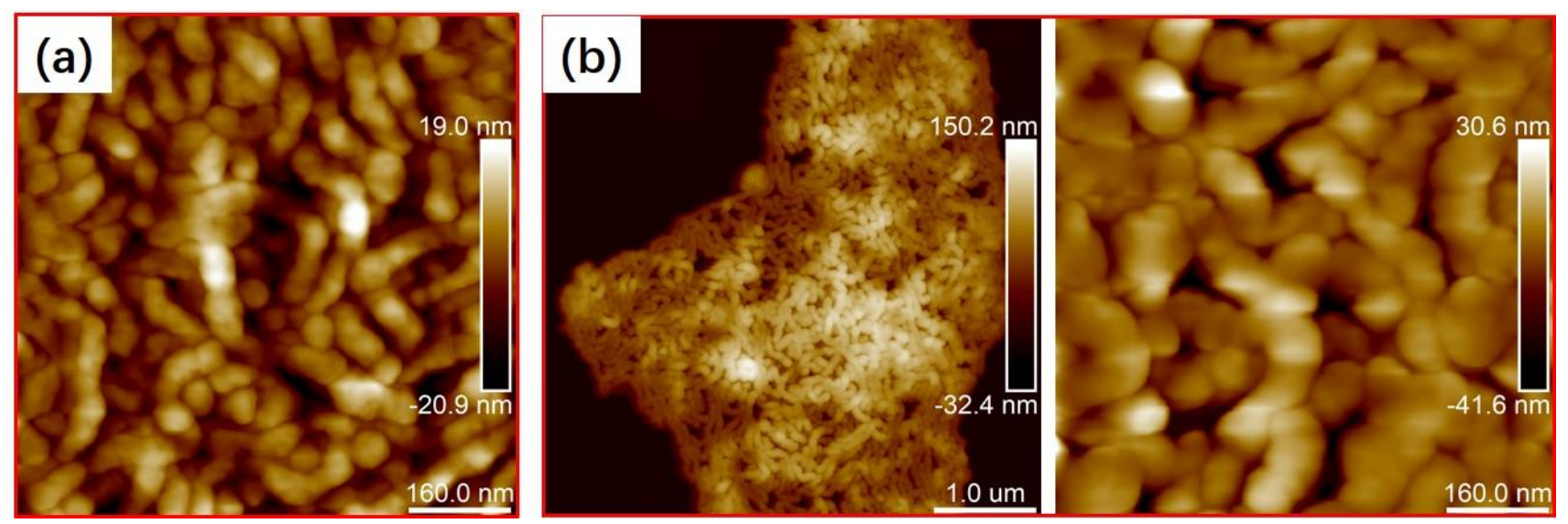

Figure S17. AFM images of (a) PPEGMA $15-\mathrm{P}\left(\mathrm{HPMA}_{275}-\mathrm{co}-\mathrm{ALAM}_{14}\right)-\mathrm{P}\left(\mathrm{NIPAM}_{300}-\mathrm{co}-\mathrm{ALAM}_{14}\right)$ and (b) PPEGMA $15-\mathrm{P}\left(\mathrm{HPMA}_{275}-\mathrm{co}-\mathrm{ALAM}_{14}\right)-\mathrm{P}\left(\mathrm{NIPAM}_{600}-\mathrm{co}-\mathrm{ALAM}_{28}\right)$ cylindrical micelles prepared by seeded photo-PISA at $35{ }^{\circ} \mathrm{C}$.

\section{Reference}

(1) Moad, G.; Chong, Y. K.; Postma, A.; Rizzardo, E.; Thang, S. H. Advances in RAFT Polymerization: The Synthesis of Polymers with Defined End-Groups. Polymer 2005, 46 (19), 8458-8468. https://doi.org/10.1016/j.polymer.2004.12.061. 
(2) Qu, Q.; Liu, G.; Lv, X.; Zhang, B.; An, Z. In Situ Cross-Linking of Vesicles in PolymerizationInduced Self-Assembly. ACS Macro Lett. 2016, $5 \quad$ (3), 316-320. https://doi.org/10.1021/acsmacrolett.6b00066.

(3) Li, G.; Xu, N.; Yu, Q.; Lu, X.; Chen, H.; Cai, Y. Acceleration and Selective Monomer Addition during Aqueous RAFT Copolymerization of Ionic Monomers at $25{ }^{\circ} \mathrm{C}$. Macromol. Rapid Commun. 2014, 35 (16), 1430-1435. https://doi.org/10.1002/marc.201400153. 